\title{
Factors associated with hospital arrival time after the onset of stroke symptoms: A cross-sectional study at two teaching hospitals in Harare, Zimbabwe
}

\author{
Farayi Seremwe', Farayi Kaseke ${ }^{2}$,Theodora M. Chikwanha ${ }^{2}$, Vasco Chikwasha ${ }^{3}$ \\ 1. Harare Central Hospital, Harare, Zimbabwe \\ 2. Department of Rehabilitation, College of Health Sciences, University of Zimbabwe, Harare, Zimbabwe \\ 3. Department of Community Medicine, College of Health Sciences, University of Zimbabwe, Harare, Zimbabwe
}

Correspondence: Ms Theodora M. Chikwanha (middychiky@yahoo.co.uk)

\section{Background \\ Abstract}

Late presentation to hospital after onset of stroke affects management and outcomes of the patients. This study aimed to determine the factors associated with time taken to present to hospital after the onset of acute stroke symptoms.

Methods

A descriptive cross sectional study was conducted at two teaching hospitals in Zimbabwe. Participants included patients admitted with stroke and their relatives. A self-administered questionnaire was used to collect information on history of stroke occurrence and time taken to present to hospital. Data was analysed for means, frequencies, percentages and Odds ratios.

Results

Less than half $(33 \%)$ of the participants were able to recognize symptoms of stroke. Not having money to pay for hospital bills was a predictor of late hospital presentation (OR $=6.64 ; 95 \% \mathrm{CI},(2.05-21.53) ; \mathrm{p}=0.002)$. The other factors, though not statistically significant included not perceiving stroke as a serious illness $(\mathrm{OR}=2.43 ; 95 \% \mathrm{CI}(0.78-5.51) ; \mathrm{p}=0.083)$ and unavailability of transport $(\mathrm{OR}=2.33$; $95 \%$ CI $(0.71-7.56) ; \mathrm{p}=0.161)$. Predictors for early presentation included receiving knowledge about stroke from the community $(\mathrm{OR}=0.46 ; 95 \% \mathrm{CI}(0.15-1.39) ; \mathrm{p}=0.170)$; seeking help at the hospital $(\mathrm{OR}=0.50 ; 95 \% \mathrm{CI}(0.18-1.37)$; $\mathrm{p}=0.177)$ and having a stroke while at the workplace $(\mathrm{OR}=0.46 ; 95 \% \mathrm{CI}(0.08-2.72) ; \mathrm{p}=0.389)$.

Conclusions

Regarding stroke as an emergency that does not require prerequisite payment for services at hospitals and improved community awareness on stroke may improve time taken to present to hospital after the onset of stroke symptoms.

\section{Introduction}

Early hospital presentation after an acute stroke enables prompt medical management. This will result in successful treatment and improved patient outcomes. ${ }^{1}$ However, cumulative time spent without medical intervention after acute stroke contributes to increased mortality and morbidity. ${ }^{2}$ The outcome of a stroke can be made worse by failure to promptly start medical management as well as detect and deal adequately with the complications of stroke in the acute stage. ${ }^{2,3}$ In order to reduce disability and mortality following a stroke, health professionals are recommended to assess for dysphagia, use antiplateletes following CT scan confirmation of ischaemia, admit the patient to a dedicated stroke unit and attend to hydration and nutrition. ${ }^{4}$ Medical intervention has the ability to manage and prevent complications of stroke thereby improving the long term prognosis of acute strokes. It is important to note that prevention of stroke uses less resources compared to managing the complications of actual stroke when they occur. ${ }^{2,5}$ Successful outcome is based on early recognition of stroke, transportation to the hospital emergency department immediately after stroke, timely imaging, proper diagnosis and thrombolysis within 4.5 hours.

It is vital to ensure that people with acute stroke present to hospital for medical management on time. The biggest huddles for early hospital presentation in India were inability by patients, relatives and physicians to recognize the symptoms of stroke as well as lack of imaging services and inability to pay for some of the services and lack of transport. ${ }^{7}$ Stroke complications occur within days and include haemorrhagic transformations of ischaemic strokes, cerebral oedema accompanied by cerebral herniation, myocardial infarction, seizures, gastrointestinal bleeding, deep vein thrombosis, aspiration pneumonia and death. $8,9,10$

The actual time taken to present to hospital following the onset of acute stroke and the factors associated with time to present to hospital among Zimbabweans are not known. Knowledge and perceptions about stroke and its symptoms among the family members of people that had suffered a stroke may have a bearing on the time taken to present to hospital hence the study upon which this paper is based. In Parkistan, low levels of awareness and general education, rampant alternative therapies and lack of adequate health transport systems prolongs time to seek treatment. ${ }^{11}$ A dedicated ambulance service was recommended by Mosley et al. to reduce pre hospital time. ${ }^{12}$

Poor identification of stroke symptoms in developing countries was found by Bachadi. ${ }^{6}$ Not regarding symptoms as serious due to lack of knowledge was another reason for delay by patients. Relatives were also found to lack knowledge in recognizing stroke symptoms hence a need to educate the general public for enlightenment about stroke and the need to act timeously.

Management of stroke is costly. These costs include costs for inpatient stay, outpatient visits, rehabilitation, medications and institutionalisation. ${ }^{13}$ In 2009 the estimated annual direct 
Table 1: Sociodemographic characteristics of patients with stroke $(\mathrm{N}=121)$

\begin{tabular}{cl}
\hline Demographic characteristic & Frequen \\
\hline Marital status & \\
Married & $74(61)$ \\
Single & $5(4)$ \\
Widowed & $37(31)$ \\
Divorced & $5(4)$
\end{tabular}

Residence

$\begin{array}{ll}\text { Urban } & 80(66) \\ \text { Rural } & 41(34)\end{array}$

Living status

Alone

Not alone

Highest level of education

No education

Primary

Secondary

$32(26)$

Tertiary

\section{Employment status}

$\begin{array}{ll}\text { Working } & 46(38) \\ \text { Not working } & 49(41) \\ \text { Retired } & 26(21)\end{array}$

Monthly income (USD)

$\$ 0$

$\$ 1$ to 100

$\$ 101$ to 300

$20(17)$

$\$ 301$ to 500

$9(7)$

\section{Religion}

Pentecostal

$14(12)$

Catholic/Protestant

$63(52)$

Apostolic

$34(28)$

Atheist

\section{Hospital patient presented to}

Parirenyatwa

$61(50.4)$

Harare

$60(49.6)$

\section{Mode of payment for hospital services}

$\begin{array}{ll}\text { Cash } & 54(44) \\ \text { Medical aid } & 8(7) \\ \text { Aged non-paying } & 59(49)\end{array}$

costs for stroke was reported to be US $\$ 22.8$ billion in the United States, ${ }^{14}$ while Gustavsson ${ }^{15}$ estimated 26.6 billion Euros for the EU in 2010. Indirect costs include loss of productivity and costs of informal caregiving provide by unpaid family caregivers and these are reported to be huge. ${ }^{13}$ Zimbabwe may face the same challenges more so as it is a developing country and many patients may not afford these costs hence the need for free health care for stroke patients.

The purpose of this study was to assess the reasons for delay in stroke patients accessing hospital services at two hospitals in Zimbabwe after the onset of symptoms of stroke.

\section{Methods}

A descriptive cross sectional study was conducted at two teaching hospitals namely Parirenyatwa and Harare http://dx.doi.org/10.4314/mmj.v29i2.18
Central Hospitals in Zimbabwe. Permission to carry out the study in the hospitals was granted by the institutional ethical committees. Ethical approval was obtained from the relevant Institutional Review Boards (JREC 20/13 and MRCZ/B/563). Informed consent was sought from caregivers and people who had survived a stroke.

Patients with a clinical diagnosis of acute stroke or a computed tomography (CT) scan that confirmed a stroke and their caregivers were recruited into the study. The patients who were included were above 18 years with a first ever diagnosis of stroke. The patients and their caregiver were treated as a unit. The patients were identified through the ward registers in the medical wards. The caregivers were identified and approached during hospital visiting times. A self-administered questionnaire was completed by the caregivers. The patients' socio-demographic and medical data were extracted from the in-patient case files and transcribed onto a data abstraction sheet. The questionnaire focused on participants' knowledge of stroke symptoms, their response after the onset of the symptoms and the time taken to get the patient to the nearest health care facility. Information was also elicited about the events between stroke onset and hospital presentation.

Data was entered into Excel and exported to Stata 13 for analysis. Missing data was treated as missing during analysis. Data was analysed for means and frequencies. Odds ratios were computed for factors associated with hospital presentation time according to early ( $\leq 3$ hours) or late $>$ 3 hours) hospital presentation categories. Logistic regression modelling of these factors was then performed to determine the independent predictors of early presentation to hospital following the onset of a stroke.

\section{Results}

A total of 121 stroke survivors were enrolled into the study. Sixty one patients were recruited from Parirenyatwa hospital whilst sixty patients were recruited from Harare hospital.

\section{Sociodemographic characteristics}

The mean age of patients was $61.5+17.5$ years. The majority $(63.6 \%)$ of patients were females who were married $(61 \%)$, did not live alone $(92 \%)$ and lived in the urban areas $(66 \%)$. Sixty percent of the patients had their highest level of education at primary level. Less than half $(38 \%)$ of the survivors were currently working and the rest had no source of income (Table 1).

Diagnosis was mainly based on signs and symptoms with only $46(38 \%)$ patients having had CT scan done. Thirtythree $(72 \%)$ of the CT scans confirmed ischaemic stroke while thirteen $(28 \%)$ showed signs of a haemorrhagic stroke.

\section{Knowledge of stroke symptoms among participants}

Thirty-three percent of the participants reported that they were able to recognize the symptoms of stroke by responding yes or no to a question on their ability to recognize the stroke symptoms. Fifty per cent perceived the stroke illness as being serious. Fifty-three percent of the participants mentioned hypertension/high blood pressure as a risk factor for stroke. Other risk factors were stress, diabetes and defaulting treatment. Eighty-five $(70 \%)$ perceived medical management as the only effective treatment for stroke while the remaining 32 considered other alternative treatments such as faith healing, traditional/herbal medicine or others. The major source of knowledge about stroke was from the community (Table 2).

Malawi Med J. 2017 Jun;29(2):171-176 
Table 2: Knowledge of stroke symptoms among participants

\begin{tabular}{ll}
\hline Knowledge of stroke & Frequency (\%) \\
\hline Ability to recognize stroke symptoms $(\mathbf{N}=\mathbf{1 2 1})$ & \\
Yes & $40(33)$ \\
No & $81(67)$ \\
Perception of stroke illness being serious $(\mathbf{N}=\mathbf{1 2 1})$ & \\
Yes & $61(50.4)$ \\
No & $60(49.6)$ \\
Perceived causes of stroke $(\mathbf{N}=\mathbf{1 2 1})$ & \\
High blood pressure & $64(53)$ \\
Stress & $23(19)$ \\
Diabetes & $7(6)$ \\
Witchcraft & $1(1)$ \\
Drug reaction & $2(2)$ \\
Overworking & $6(5)$ \\
Defaulting diabetes/hypertension drugs & $4(3)$ \\
Overweight & $3(2)$ \\
Unfit & $1(1)$ \\
Don't know & $10(8)$ \\
Hereditary & $2(2)$ \\
Circulation problems & $2(2)$ \\
HIV/AIDS & $1(1)$ \\
Alternative non-medical treatment sought $(\mathbf{n}=\mathbf{3 2})$ & \\
Faith healing & $24(76)$ \\
Traditional/herbal & $5(16)$ \\
Other & $3(9)$ \\
Sources of knowledge about stroke (n = 100) & \\
Medical personnel & $44(44)$ \\
Community & $51(51)$ \\
Self-sought knowledge & $5(5)$ \\
\hline
\end{tabular}

\section{Factors affecting hospital arrival time after the onset of stroke}

The shortest time to present to hospital was 43 minutes (0.72hrs), and the longest time to present to hospital was 240 hours (10 days). Lack of readily available money to pay for hospital fees at the time of stroke was found to be a significant predictor of late hospital presentation (OR, 6.64; 95\% CI, (2.05-21.53); $\mathrm{p}=0.002)$.

The other factors that affected time taken to present to hospital were; not perceiving stroke as a serious illness (OR, 2.43; 95\% CI, (0.89-6.65); $\mathrm{p}=0.083)$, not having readily available transport to ferry the stroke patient to hospital $(\mathrm{OR}, 2.07 ; 95 \% \mathrm{CI},(0.78-5.51) ; \mathrm{p}=0.144)$ and residing in the rural areas when the stroke occurred (OR, $2.33 ; 95 \%$ CI, (0.71-7.56); $\mathrm{p}=0.161)$. However, all these were not statistically significant.

The factors that prompted early hospital presentation time were; receiving knowledge about stroke from the community (OR, 0.46; 95\% CI (0.15-1.39); $\mathrm{p}=0.170)$, seeking help first at the hospital rather than at other places (OR, 0.50;95\% CI (0.18-1.37); $\mathrm{p}=0.177)$ and having a stroke whilst at work (OR, 0.46; 95\% CI (0.08 -2.72); $\mathrm{p}=0.389)$. These were also not statistically significant (Table 3 ).

\section{Discussion}

The findings from this study reveal that stroke generally occurs in older women $(63.6 \%)$. This is most likely because women live longer than men. However Walker ${ }^{16}$ attributed this to age structure of denominator populations which may be the same for Zimbabwe. ${ }^{17} \mathrm{~A}$ higher age adjusted prevalence rate among women compared to men was found among stroke survivors. ${ }^{18}$ In addition stroke, particularly in low and middle income countries is increasing particularly in the young with more than 83,000 children and youths under 20 years being affected annually in both low and middle income countries. ${ }^{19}$ http://dx.doi.org/10.4314/mmj.v29i2.18
These authors refuted the thought that stroke was a disease of the aged as they found a higher burden of stroke in those below 75 years. They also reported an increased proportion of stroke among those below 64 years and this finding led them to conclude that stroke can no longer be regarded as a disease of the aged. This is consistent with findings from studies done elsewhere. ${ }^{20-24}$

More than half of the stroke survivors in this study were married, and in addition the majority of the patients did not live alone. Studies have shown that not being alone at the time of a stroke prompts early hospital presentation as there are other people at hand to take the patient to hospital. The dominance of ischaemic strokes over haemorrhagic strokes is consistent with findings worldwide. ${ }^{23,25-28}$ The proportion of cerebral haemorrhage of around 30\% is in keeping with hospital studies elsewhere in Africa, but higher than in community studies in higher income regions ${ }^{18}$ and in the only community-based stroke study in Africa. ${ }^{16}$ In general, ischaemic stroke is more common because of the pathogenesis e.g. cardiac emboli, atherosclerotic disease, hypertension causing small vessel disease which outweigh the causes of cerebral haemorrhage; the underlying causes changes in populations as predicted by the epidemiological transition. Hospital based study bias which favours more severe strokes like cerebral haemorrhage increases the proportion. ${ }^{18}$

Participants in this study were drawn from major referral hospitals in the country which cater for both urban and rural populations in Zimbabwe. There were more patients from urban areas where the hospitals are situated although in Zimbabwe $65 \%$ of the population resides in rural areas. ${ }^{17}$ This finding may imply more prompt hospital presentation for urban stroke patients compared to their rural counterparts. Stroke patients in rural areas have access to basic health facilities located in rural areas which have a low capacity to manage strokes as they lack requisite resources thus the need to travel to the referral hospitals for stroke management. ${ }^{27}$ Residing in the rural areas when the stroke occurred was associated with increased delay in hospital presentation as compared to living in the urban areas. However it is important to note that rural areas in Zimbabwe tend to be further in the margins of urban areas thereby increasing the distance the patients have to travel to receive medical attention in the hospitals being studied. In addition, they tend to have poorer transport systems delaying eventual hospital presentation compared to those already in urban areas.

In this study, the majority of the patients had their highest education at the primary level. Despite the low levels of stroke symptoms recognition generally reported by these participants most of them reported the cause of stroke to be high blood pressure. Elsewhere, higher levels of education starting from secondary school onwards have been associated with good knowledge of symptoms of stroke. $^{29-32}$ In Nigeria, Philip-Ephraim ${ }^{1}$ found that more than half of their participants had no knowledge of stroke symptoms. Even though most of the participants in our study had some formal education with the majority having primary education, the impact of spirituality and traditional beliefs cannot be ruled out as a factor affecting time to present to hospital in Zimbabwe. This is supported by the findings that some participants would seek help elsewhere before presenting to hospital.

Although $50 \%$ of the participants perceived stroke as a 
Table 3: Factors contributing to hospital arrival time after stroke onset

\begin{tabular}{|c|c|c|c|c|}
\hline \multirow{2}{*}{ Factors } & \multicolumn{2}{|c|}{$\begin{array}{c}\text { Time to hospital } \\
\text { presentation }\end{array}$} & \multirow{2}{*}{$\begin{array}{c}\text { Odds ratio ( } 95 \% \\
\text { confidence interval) }\end{array}$} & \multirow[b]{2}{*}{ P-value } \\
\hline & $\begin{array}{c}\text { Late } \\
\text { (> } 3 \text { hours) }\end{array}$ & $\begin{array}{c}\text { Early } \\
(\leq 3 \text { hours })\end{array}$ & & \\
\hline \multicolumn{5}{|l|}{ Gender } \\
\hline Male & 30 & 7 & Reference & \\
\hline Female & 52 & 14 & $0.87(0.31$ to 2.39$)$ & 0.78 \\
\hline \multicolumn{5}{|l|}{ Residence } \\
\hline Urban & 53 & 17 & Reference & \\
\hline Rural & 29 & 4 & $2.33(0.71$ to 7.56$)$ & 0.16 \\
\hline \multicolumn{5}{|l|}{ Education level } \\
\hline No education & 8 & 3 & Reference & \\
\hline Primary & 49 & 14 & $1.31(0.31$ to 5.62$)$ & 0.71 \\
\hline Secondary & 23 & 3 & $2.88(0.48$ to 17.24$)$ & 0.25 \\
\hline Tertiary & 2 & 1 & $0.75(0.05$ to 11.65$)$ & 0.84 \\
\hline \multicolumn{5}{|l|}{ Living status } \\
\hline Alone & 4 & 2 & Reference & \\
\hline Not alone & 78 & 19 & $2.05(0.35$ to 12.05$)$ & 0.43 \\
\hline \multicolumn{5}{|l|}{ Place of stroke } \\
\hline Home & 70 & 16 & Reference & \\
\hline Work & 4 & 2 & $0.46(0.08$ to 2.72$)$ & 0.39 \\
\hline Other & 8 & 3 & $0.61(0.15$ to 2.56$)$ & 0.50 \\
\hline \multicolumn{5}{|l|}{ First stroke event } \\
\hline Yes & 60 & 18 & Reference & \\
\hline No & 22 & 3 & $2.20(0.59$ to 8.20$)$ & 0.24 \\
\hline \multicolumn{5}{|l|}{$\begin{array}{l}\text { Perception of stroke as } \\
\text { serious illness }\end{array}$} \\
\hline Yes & 37 & 14 & Reference & \\
\hline No & 45 & 7 & $2.43(0.89$ to 6.65$)$ & 0.083 \\
\hline \multicolumn{5}{|l|}{ Severity of stroke } \\
\hline Conscious & 81 & 18 & Reference & \\
\hline Unconscious & 14 & 2 & $1.43(0.29$ to 7.06$)$ & 0.66 \\
\hline \multicolumn{5}{|l|}{$\begin{array}{l}\text { Company at time of } \\
\text { stroke }\end{array}$} \\
\hline Alone & 16 & 4 & Reference & \\
\hline Not alone & 65 & 17 & $0.96(0.28$ to 3.23$)$ & 0.94 \\
\hline \multicolumn{5}{|l|}{$\begin{array}{l}\text { Prior stroke } \\
\text { management at } \\
\text { different facility } \\
\text { (medical/non-medical) }\end{array}$} \\
\hline Yes & 41 & 7 & Reference & \\
\hline No & 41 & 14 & $0.50(0.18$ to 1.37$)$ & 0.18 \\
\hline \multicolumn{5}{|l|}{$\begin{array}{l}\text { Readily available } \\
\text { hospital fees }\end{array}$} \\
\hline Yes & 32 & 17 & Reference & \\
\hline No & 50 & 4 & $6.64(2.05$ to 21.53$)$ & $0.002^{*}$ \\
\hline \multicolumn{5}{|l|}{$\begin{array}{l}\text { Readily available } \\
\text { transport to hospital }\end{array}$} \\
\hline Yes & 25 & 10 & Reference & \\
\hline No & 57 & 11 & $2.07(0.78$ to 5.51$)$ & 0.14 \\
\hline \multicolumn{5}{|l|}{$\begin{array}{l}\text { Mode of transport to } \\
\text { hospital }\end{array}$} \\
\hline Private transport & 50 & 16 & Reference & \\
\hline Ambulance & 9 & 0 & - & \\
\hline Public transport & 23 & 5 & $1.47(0.48$ to 4.51$)$ & 0.50 \\
\hline \multicolumn{5}{|l|}{ Prior stroke in family } \\
\hline Yes & 39 & 11 & Reference & \\
\hline No & 43 & 10 & $1.21(0.46$ to 3.17$)$ & 0.69 \\
\hline \multicolumn{5}{|l|}{$\begin{array}{l}\text { Source of knowledge } \\
\text { about stroke causes }\end{array}$} \\
\hline Medical personnel & 38 & 6 & Reference & \\
\hline Community & 43 & 16 & $0.46(0.15$ to 1.39$)$ & 0.17 \\
\hline
\end{tabular}

*Significant at $\alpha=0.05$

serious illness, not all of them presented early to hospital. The ideal recommended time to present an acute stroke patient to hospital is within 3 hours. ${ }^{2,33}$ In this study most of the patients presented to hospital more than three hours after the stroke had occurred. This delay could have been due to multiple factors. Firstly, having no money to pay for hospital fees at the time of stroke was found to be the only significant predictor of late hospital arrival in our study. Inability to afford hospital fees and seeking help elsewhere were found to have contributed to delays in presenting to hospital, similar to findings in other studies. ${ }^{34-38}$ A study http://dx.doi.org/10.4314/mmj.v29i2.18 done in Malawi found that higher education levels and better socio economic status and social support resulted in better outcomes post stroke. ${ }^{39}$ Secondly it is important to note that during the time this study was conducted, there was an economic crisis in Zimbabwe and most health care facilities were asking for cash payment for services before they could attend to the patients. This might have contributed significantly to the delays in presenting to hospital. There is need for hospitals and policy makers to consider suspending the upfront payment of user fees for acute stroke patients who cannot afford it.

Unavailability of transport to ferry the stroke patient to hospital was associated with delayed hospital presentation. Other studies also reported that additional time spent acquiring enough money to pay for the alternative transport and additional distance to board the transport delayed further the hospital presentation time..$^{38,40-42}$ In Malawi public transport has been found to be difficult, inconvenient and too challenging to use due to distance and inconsistence availability. ${ }^{43}$ This may also affect presentation to hospital. Several studies conducted in various settings recommend the use of emergency medical services or ambulances as the ideal, efficient mode of transportation to hospital after an acute stroke. ${ }^{5,35-38}$ However, in this study the few patients who were taken to hospital by ambulance did not get to hospital within the recommended time. This can be attributed to the high user fees (on average US $\$ 40$ ) often required upfront in order to call an ambulance for private use in Zimbabwe yet the majority of the participants earned less than $\$ 300$ per month. This could have deterred the majority of stroke patients who had no money available at the time the stroke occurred from calling an ambulance when the stroke occurred. There is need to make the local authority ambulances readily available for use by community dwellers in cases of medical emergencies such as a stroke or have a dedicated ambulance service for stroke. ${ }^{12}$

Seeking the first help after an acute stroke at a hospital that has the capacity to manage strokes has been found to help prompt acute stroke hospital presentation. ${ }^{32}$ Going to clinics or other medical institutions that do not have the capacity to manage strokes only to be referred, further delays arrival at the appropriate hospital. ${ }^{38}$ The findings in this study also alluded to the perception of the stroke patients and their caregivers to alternative stroke management by apostolic healing, spiritual healing and use of herbal medicines. In addition, Hundt et al. ${ }^{44}$ reported that stroke is considered to be both a physical and social condition, and consequently plural healing using clinical and social diagnostics is sought. In their study on "secondary prevention of stroke." Thorogood45 found that stroke survivors sought help from allopathic health care as well as from traditional healers and churches. There may be need to appreciate that some of the patients may delay presenting to hospital as they first seek these alternative therapies.

The factors that prompted early hospital presentation time were, receiving knowledge about stroke from the community and seeking help first at hospital rather than elsewhere. In this study, the majority of patients received their knowledge about stroke from the community as compared to receiving it from medical personnel. Interestingly however, receiving knowledge about stroke from the community compared to medical personnel turned out to be protective of delayed hospital presentation. This spells the need to revise the 
current stroke awareness campaigns. Several countries in Sub Saharan Africa including Zimbabwe, Nigeria, Tanzania, Malawi and South Africa led by Stroke organisations commemorate the World Stroke Day on the 29th of October each year to increase awareness on stroke. There is also an annual disability awareness day held in Zimbabwe every December led by Rehabilitation personnel at the public institutions. This involves marching in communities with banners and pamphlets distributed. School children and local authorities are also involved as well as the disabled people. The marches culminate with a gathering where people are taught about prevention, early identification, referral and management of different conditions.

It is therefore recommended that opportunities to educate the communities about stroke and its symptoms by healthcare workers be harnessed through activities such as awareness campaigns at primary health care facilities where most patients report to first before they can be referred to secondary or tertiary health care institutions. While it was beyond the scope of this study to evaluate how the communities prefer to be educated on stroke and its symptoms, it can be assumed that people are more accepting of information from their neighbours hence they act on their advice. A recommendation to use applied theatre in the dissemination and communication of information for awareness campaigns was made. ${ }^{46}$ This is because theatre is frequently used in health promotion, education and training.

\section{Conclusions}

The factors identified to be contributing to delays in hospital presentation in this study are modifiable. Intervention by relevant authorities may positively influence the time taken to present to hospital.

\section{Acknowledgements}

Appreciation is expressed to the participating hospitals, the people who suffered a stroke and their relatives who responded to the questions.

\section{Competing interests}

The authors declare no financial or personal relationships that may have inappropriate effects on the outcomes of this research.

\section{References}

1.Philip -Ephraim EE, Charidimou A, Out AA, et al. Factors associated with pre hospital delay among stroke patients in a developing African country. Int J Stroke 2015; 10

2. Kitchener N, Hashem S, Wahba M, Khalaf M, Zarif B, Mansoor $\mathrm{S}$. The flying publisher guide to critical care in neurology. Flying Publisher; 2012.

3. Rothwell PM, Giles MF, Chandratheva et al. Effect of urgent treatment of transient ishaemic attack and minor stroke on early recurrent stroke (EXPRESS study): A prospective population based sequential comparison. Lancet 2007; 370 (9596):1432-42.

4. Langhorne P, Pollock A. What are the components of effective stroke unit care? Age and Ageing. 2002; 31: 365-371.

5. Maestroni A, Mandelli C, Mangano D et al. Factors influencing delay in presentation for acute stroke in an emergency department in Milan, Italy. Emerg Med J 2008; 25 (6): 340-5.

6. Badachi S, Mathew T, Prabhu A, Nadig R, and Sarma GRK. Hurdles in stroke thrombolysis: Experience from 100 consecutive ischemic stroke patients. Ann Indian Acad Neurol. 2015; 18(4): 415-418.

7. Pandian JD, Sethi V, Dhillon R et al. Is intravenous thrombolysis feasible in a developing country? Cerebrovascular Dis. 2005;20:134-6 http://dx.doi.org/10.4314/mmj.v29i2.18
8. Lee DK, Kim JS, Kwon SU, Yoo SH, Kong DW. Lesion Patterns and Stroke Mechanism in Atherosclerotic Middle Cerebral Artery Disease: Early Diffusion Weighted Imaging Study. Stroke 2005; 36(12):25382588.

9. Mullins ME, Lev MH, Schellingerhout D, Gonzalez RG, Schaefer PW. Intracranial hemorrhage complicating acute stroke: how common is hemorrhagic stroke on initial head CT scan and how often is initial clinical diagnosis of acute stroke eventually confirmed? AJNR Am J Neuroradiol 2005; 26 (9):2207-12.

10. Kumar S, Selim MH, Caplan LR. Medical complications after stroke. Lancet Neurol 2010; 9(1):105-18.

11. Asad Mahmood, Muhammad Ashraf Sharif, Umar Zafar Ali, Muhammad Naeem Khan. Time to Hospital Evaluation in Patients of acute stroke for Alterplase Therapy.

12. Mosley I, Nicol M, Donnan G et al. The impact of ambulance practice on acute stroke care. Stroke. 2007; 38:2765-70.

13.Joo H, George MG, Fang J, Wang G. A literature review of indirect costs associated with stroke. J Stroke Cerebrovasc Dis. 2014; 23(7): 1753-1763.

14. Go AS, Mozaffarian D, Roger VL, Benjamin EJ, Berry JD, Borden WB, et al. Heart disease and stroke statistics - 2013 update: A report from the American Heart Association. Circulation, 2013; 127:e6-e245.

15. Gustavsson A, Svensson M, Jacobi F, Aligulander C, Alonso J, Beghi E, et al. Cost of disorders of the brain in Europe 2010. European neuropsychopharmacology. 2011;21:718-779.

16. Walker R, Whiting D, Unwin N, et al. Stroke in rural and urban Tanzania: a prospective community-based study. Lancet Neurol 2010; 9:786-92.

17. Population Census National Report 2012-Zimstat. Available at www.zimstat.co.zw.

18. Connor M D, Walker Richard, Modi G, warlow CP. Burden of stroke in black populations in sub-Saharan Africa. Lancet Neurol 2007; 6:269-78.

19. Feigin VL, Forouzanfar MH, Krishnamurthi R et al. Global and regional burden of stroke during 1990-2010: findings from the Global Burden of Disease Study 2010. Lancet 2014;383:245-55.

20. AL-Oraibi S. Demographic characteristics of stroke patients in developing countries: Example from Jordanian Government hospital. J Public Health Epidemiol 2012; 4(5):110-116.

21. Siddiqui M, Siddiqui SR, Zafar A, Khan FS. Factors delaying hospital arrival of patients with acute stroke. J Pak Med Assoc 2008; 58(4):178-182

22. Mandelzweig L, Goldburt V, Boyko V, Tanne D. Perceptual, Social, and behavioural factors associated with delays in seeking Medical Care in patients with symptoms of acute stroke. Stroke 2006; 37(5):1248-53.

23. Bereczki D, Milhalka L, Fekete I. The Debrecen Stroke database: demographic characteristics, risk factors, stroke severity and outcome in 8088 consecutive hospitalized patients with acute Cerebrovascular disease. Int J Stroke 2009; 4 (5):335-9.

24. Foerch C, Ghandehari K, Xu G, Kaul S. Exploring gender distribution in patients with acute stroke: A multinational approach. J Res Med Sci 2013; 18(1):10-6.

25. Derex L, Adelaine P, Nighoghosian N, Honorrat J, Trouillas P. Factors influencing early admission in a French stroke unit. Stroke 2002; 33(1):153-9.

26. Mudzi W,Stewart A,Musenge E.Case fatality of patients with stroke over a 12 month period post stroke.S Afr Med J 2012;102(9):765-7.

27. De Villiers L, Badri M, Ferreira M et al. Stroke outcomes in socioeconomically disadvantaged urban community. S Afr Med J 2011; 101(5):345-348. 
28. Abboud H, Labreuche J, Arauz A et al. Demographic, socioeconomic characteristics, and risk factor prevalence in patients with non-cardio-embolic ischaemic stroke in low and middle income countries: the OPTIC registry. Int J Stroke 2013;100 (8):4-13.

29. Shihabi A. Differences in the knowledge of stroke symptoms between urban and rural population. Acta Clin Croat 2007; 46:235-239.

30. Sekoranja L, Griesser AC Wagner G et al. Factors influencing emergency delays in acute stroke management. Swiss Med Wkly 2009; 139 (27-28):393-99.

31. Evenson KR, Foraker R, Morris DL, Rosamond WD. A comprehensive review of pre-hospital and in hospital delay times in acute stroke care. Int J Stroke 2009; 4:187-99

32. Pandian JD, Kalra G, Jaison A et al. Knowledge of stroke among stroke patients and their relatives in Northwest India. Neurology India 2006; $54: 2: 153-9$.

33. Hemphill JC 3RD, Grenberg SM, Anderson CS. Guidelines for the management of spontaneous intracerebral hemorrhage: a guideline for healthcare professionals from the American Heart Association/ American Stroke Association. Stroke 2015; 46 (7); 2032-60.

34. Kim HJ, Ahn JH, Kim SH, Hong ES. Factors associated with prehospital delay for acute stroke in Ulsan Korea. J Emerg Med 2010; 4(1):59-63.

35. Faiz K, Sundseth A Thommersen B, Ronning OM. Pre-hospital delay in acute stroke and T.I.A. Emerg Med J 2013;30(8): 669-674.

36. Ekeh B and Isamade E. Time of presentation of stroke patients in a tertiary hospital in Northern Nigeria, West Africa. J Med Investig Prac 2014; 9(1):1-4.

37. Srivastava AK, Prasad K. A study of factors delaying hospital arrival of patients with acute stroke, Neurol India. 2001; 49(3):272-6.
38. Tang D, Reeves MJ, Hernandez AF, Zhao X, Olson DM, Fonarrow $\mathrm{GC}$ et al. Times from symptom onset to hospital arrival in Get with the Guidelines- Stroke Programme 2002-2009: Temporal trends and implication. Stroke 2012; 43 (7)1912-7.

39.Heikinheimo T, Chimbayo D. Quality of life after first -ever stroke: An interview based study from Blantyre, Malawi. Malawi Medical Journal. 2015; 27(2):50-54.

40. Kleindorfer D, Lindsell CJ, Broderick JP, Flaherty ML, Woo D, Ewing I et.al. Community socioeconomic status and pre-hospital times in acute stroke and T.I.A. Stroke 2006; 37(6): 1508-

41. Akinyemi R.O, Ogah OS, Ogundipe RF, Oyesta OA, Oyadoke AA. Knowledge and perception of stroke among hospital workers in an African hospital. Euro J Neurol. 2009; 16(9): 998-1003

42. Chang KC, Tseng MC, Tan TY. Pre-hospital delay after stroke in Kaohsiung Taiwan. Stroke 2004; 35(3):700-4

43. Glickman LB, Chimatiro G, neely L, White N, Walters ES, Warres M. Community reintegration of patients with neurological disorders post discharge from Kachere Rehabilitation Centre, Malawi. Physiotherapy 2015; 101(1): e455-e456.

44. Lewando-Hundt GL, Stuttaford M, Ngoma B. The social diagnostics of stroke-like symptoms: healers, doctors and prophets in Angincourt, Limpopo Province, South Africa.J. biosoc. Sci 2004; 36:433-43.

45. Thoroggod MI, Connor MD, Lewando-Hundt G, Tollman S, Ngoma B: SASPI Project Team. Secondary Prevention of stroke - results from the Southern African Stroke Prevention Initiative (SASPI) study. Bull World Health Organ. 2004; 82(7):503-8.

46. Stuttaford M, Bryanston C, Hundt GL, Connor M, Thorogood M, Tollman S. Use of applied theatre in health research dissemination and data validation: a pilot study from South Africa. Health. 2006; 10(1); $31-45$. 